\title{
The role of sentinel node biopsy in oral squamous cell carcinoma
}

\author{
Justo Serrano-Vicente ${ }^{1,2}$ \\ ${ }^{1}$ Department of Nuclear Medicine, University Hospital Infanta Cristina, 06080 Badajoz, Spain. \\ ${ }^{2}$ Department of Biomedical Science, Extremadura University, 06071 Badajoz, Spain.
}

Address for correspondence: Dr. Justo Serrano-Vicente, Department of Nuclear Medicine, University Hospital Infanta Cristina, Av. Elvas s/n, 06080 Badajoz, Spain. E-mail: titoserrano@gmail.com

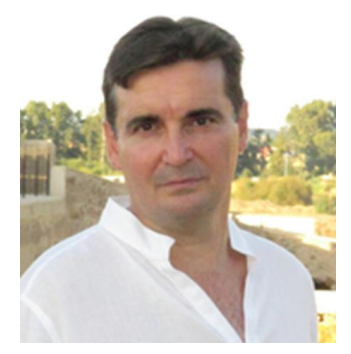

Dr. Justo Serrano-Vicente, M.D., Ph.D., is a Radiology Associated Professor in the Biomedical Science Department at Medicine Faculty of Extremadura University from 2009. He received his Ph.D. degree in Medical and Surgical Sciences from the Cantabria University, Santander, Spain, in 1995. Since 2000, he works at the Department of Nuclear Medicine, University Hospital Infanta Cristina, Badajoz, Spain.

\begin{abstract}
Aim: The purpose of this study was to conduct a systematic review of the published literature to assess the state of the art of this procedure. Sentinel node biopsy (SNB) in oral squamous cell cancer (OSCC) is a novel and proven useful technique alternative to the neck dissection (ND) in the management of OSCC. Methods: The authors searched PubMed for literature in English published for the last five years, addressing this topic. Prospective studies articles were selected with at least thirty patients studied. Results: Of 235 studies found, 14 studies met the exclusion and inclusion criteria for this review. The studies selected focused on the role of the SNB in the OSCC, advantages compared to ND and its limitations, testing different solutions and innovations that could implement the conventional procedure. Meta-analysis studies and review articles were also selected in order to perform the introduction and support the discussion. Based upon these findings authors have tried to establish the state of the art of the SNB and authors have highlighted recent advances that improve the sentinel lymphatic node biopsy technique in the future. Conclusion: SNB is an excellent staging method in OSCC and an interesting alternative to ND. The authors show the most appropriate procedures recommended in the bibliography revised in a trend to depict the actual state of the art.
\end{abstract}

Key words:

Oral cavity; squamous cell cancer; sentinel node biopsy

\section{INTRODUCTION}

Oral squamous cell carcinoma (OSCC) is predominantly a loco-regional disease. One of the most significant prognostic factors in management are the lymph node metastasis. ${ }^{[1]}$ Due to the high metastatic potential of

\begin{tabular}{|l|l|}
\hline \multicolumn{2}{|c|}{ Access this article online } \\
\hline Quick Response Code: & Website: \\
\hline & http://www.parjournal.net \\
\cline { 2 - 2 } & \\
\hline
\end{tabular}

these tumors, the presence of tumors spread to a single regional lymph node can transform a small stage I tumor to an advanced stage III or even stage IV head and neck

This is an open access article distributed under the terms of the Creative Commons Attribution-NonCommercial-ShareAlike 3.0 License, which allows others to remix, tweak and build upon the work non-commercially, as long as the author is credited and the new creations are licensed under the identical terms.

For reprints contact: service@oaepublish.com

How to cite this article: Serrano-Vicente J. The role of sentinel node biopsy in oral squamous cell carcinoma. Plast Aesthet Res 2016;3:142-9.

Received: 02-04-2016; Accepted: 29-04-2016 


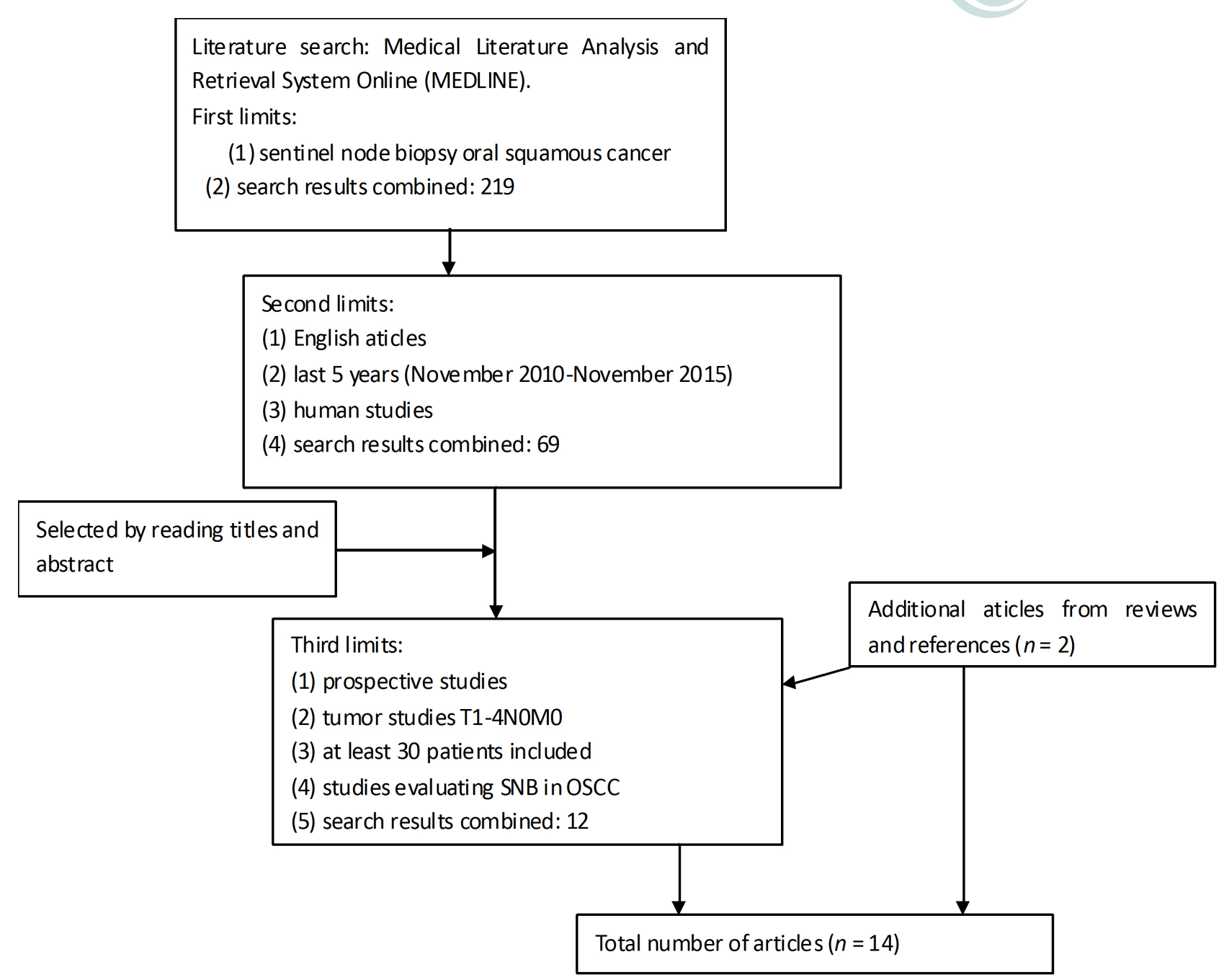

Figure 1: Literature search flow chart and selected studies form the literature according to inclusion criteria. SNB: sentinel node biopsy; OSCC: oral squamous cell cancer

cancer. The presence of a single positive lymph node can reduce disease free survival at 5 years by $50 \%$. In order to perform an adequate treatment of the neck, a correct diagnosis and staging are crucial for determining prognosis. ${ }^{[2]}$

OSCC frequently metastasizes to the cervical nodal basins, yet clinical staging with physical exam and imaging modalities [positron emission tomography-computed tomography (CT), CT scan, magnetic resonance imaging or ultrasound] usually cannot detect metastases less than 8 to $10 \mathrm{~mm}$ in size. ${ }^{[3,4]}$ Thus, for the last few years, the conventional procedure for the clinically node negative (N0) patient has been neck dissection (ND), which leads to increased loco-regional control and regional recurrencefree survival. However, ND is an aggressive procedure that represents overtreatment for approximately $70 \%$ of cN0 patients who are found to have a histological negative neck for metastases..$^{[5-7]} \mathrm{ND}$ is traditionally recommended when the tumor size and subsite confer at least a $15-20 \%$ risk of lymphatic spread. ${ }^{[8]}$ Nevertheless, in OSCC tumors that have $20 \%$ rate of nodal metastasis, the vast majority of these patients will undergo ND with no evidence of lymph node metastasis. $^{[1]}$

A conservative trend in the treatment of OSCC NO patients has encouraged the application of sentinel node biopsy (SNB). SNB entails identifying and harvesting the initial node, to which the primary tumor drains, while limiting dissection and harm to vital structures. The advantages of implementing SNB instead of ND include decreased morbidity, operating room time, and length of postoperative stay. ${ }^{[9]}$

SNB is a radio-isotopic technique that included: a peritumoral injection of adequate radiotracer that will be trapped by the regional lymphatic chains and echelons, an imaging technique capable depicting these, a radio guided surgical procedure for removing sentinel node $(\mathrm{SN})$ and a pathological study of the node that allows to know the status of the node. ${ }^{[10]}$

SNB as a staging procedure and decision tool to establish whether surgical treatment of the lymphatic area is to be performed or not, is now recognized as the gold standard in melanoma and breast cancer. ${ }^{[10,11]}$ Although the methodology of sentinel lymphatic node biopsy (SLNB) in OSCC has been well known for more than 10 years and many prospective studies with a significant number of patients have been published, it has not been accepted worldwide, where it is still considered investigational. ${ }^{[2]}$ 
Table 1: The main features of the studies selected for this systematic review

\begin{tabular}{|c|c|c|c|c|c|c|c|c|c|c|c|c|c|c|}
\hline Studies & Patients & $\begin{array}{l}\text { Mean } \\
\text { age }\end{array}$ & Staging & Injection & Tracer & $\begin{array}{l}\text { MBq } \\
\text { dose }\end{array}$ & $\begin{array}{l}\text { Volume } \\
\text { perdose }\end{array}$ & Imaging & Equipment & Surgery & $\begin{array}{l}\text { Lymph } \\
\text { nodes }\end{array}$ & Histological & SS & NPV \\
\hline $\begin{array}{l}\text { Salazar et } \\
\text { al. }{ }^{[16]} 2015\end{array}$ & 96 & 59 & TX-NO & Peritumoral & Nanocoll & 20 & $\mathrm{NA}$ & $\begin{array}{l}\text { Dynamic; } \\
\text { static } \\
\text { SPECT }\end{array}$ & $\begin{array}{c}\text { Probe; } \\
\text { porta b l e } \\
\text { camera }\end{array}$ & $\begin{array}{c}\text { Tumorectomy* + } \\
\text { SLNB +ND }\end{array}$ & $\mathrm{NA}$ & $\begin{array}{c}\text { HE; } \\
\text { SSS; } \\
\text { INMHCTK }\end{array}$ & 88 & 94 \\
\hline $\begin{array}{l}\text { Farmer et } \\
\text { al. }{ }^{17]} 2015\end{array}$ & 140 & 62 & T1-2NO & Peritumoral & SulphColl & 10 & $\mathrm{NA}$ & $\begin{array}{l}\text { Dynamic; } \\
\text { static }\end{array}$ & Probe & $\begin{array}{c}\text { Tumorectomy }^{*}+ \\
\text { SLNB +ND }\end{array}$ & $>4$ & NA & 99 & \\
\hline $\begin{array}{l}\text { Flach et } \\
\text { al[ }{ }^{[18]} 2014\end{array}$ & 62 & 61 & T1-2N0 & Peritumoral & Nanocoll & 27 & NA & $\begin{array}{l}\text { Dynamic; } \\
\text { static }\end{array}$ & $\begin{array}{c}\text { Probe; } \\
\text { BLUEDYE }\end{array}$ & $\begin{array}{l}\text { Tumorectomy* } \\
\text { SLNB + ND if } S N+\end{array}$ & 2 & $\begin{array}{c}\text { HE; } \\
\text { SSS; } \\
\text { INMHCTK }\end{array}$ & 80 & 88 \\
\hline $\begin{array}{l}\text { Hernando } \\
\text { et al. }{ }^{[19]} \\
2014\end{array}$ & 73 & 66 & T1-2NO & Peritumoral & Nanocoll & NA & $\mathrm{NA}$ & $\begin{array}{l}\text { Dynamic; } \\
\text { stati }\end{array}$ & Probe & $\begin{array}{l}\text { Tumorectomy* + } \\
\text { SLNB + ND if SN+ }\end{array}$ & 2 & $\begin{array}{c}\text { HE; } \\
\text { SSS; } \\
\text { INMHCTK }\end{array}$ & 94 & 96 \\
\hline $\begin{array}{l}\text { Bluemel et } \\
\text { al. }{ }^{[20]} 2014\end{array}$ & 23 & 58 & T1-2NO & Peritumoral & Nanocoll & $\begin{array}{c}25- \\
102\end{array}$ & $\begin{array}{c}0.05-0.1 \\
\mathrm{~mL}\end{array}$ & $\begin{array}{l}\text { Dynamic; } \\
\text { static } \\
\text { SPECT-CT }\end{array}$ & FHSPECT & $\begin{array}{l}\text { Tumorectomy§ + } \\
\text { SLNB + ND if SN+ }\end{array}$ & 3.1 & $\begin{array}{c}\text { HE; } \\
\text { SSS; } \\
\text { INMHCTK }\end{array}$ & 100 & 100 \\
\hline $\begin{array}{l}\text { Alvarez et } \\
\text { al. }{ }^{[2]} 2014\end{array}$ & 63 & 57 & T1-2NO & Peritumoral & Nanocoll & $40-50$ & $0.2 \mathrm{~mL}$ & Dynamic & Probe & $\begin{array}{l}\text { Tumorectomy* + } \\
\text { SLNB + NDif SN+ }\end{array}$ & - NA & $\begin{array}{c}\text { HE; } \\
\text { SSS; } \\
\text { INMHCTK }\end{array}$ & 100 & 86 \\
\hline $\begin{array}{l}\text { Samant }^{[12]} \\
2014\end{array}$ & 34 & 61 & T1-2NO & Peritumoral & SulphColl & 25 & $\begin{array}{c}0.1-0.3 \\
\mathrm{~mL}\end{array}$ & Dynamic & $\begin{array}{c}\text { Probe; } \\
\text { BLUEDYE }\end{array}$ & $\begin{array}{c}\text { Tumorectomy }{ }^{*}+ \\
\text { SLNB + ND if SN+; } \\
\text { /+RTX }\end{array}$ & 4 & $\begin{array}{c}\text { HE; } \\
\text { INMHCTK }\end{array}$ & 94 & 93 \\
\hline $\begin{array}{l}\text { Bell et al. }{ }^{[2]} \\
2013\end{array}$ & 36 & 57 & T1-2NO & Peritumoral & SulphColl & 15 & $\begin{array}{c}0.2-0.4 \\
\mathrm{~mL}\end{array}$ & Static & Probe & $\begin{array}{c}\text { Tumorectomy }{ }^{*}+ \\
\text { SLNB + ND }\end{array}$ & NA & $\begin{array}{c}\text { HE; } \\
\text { SSS; } \\
\text { INMHCTK }\end{array}$ & 87.5 & 96 \\
\hline $\begin{array}{l}\text { Melkane et } \\
\text { al. }{ }^{[2]} 2012\end{array}$ & 53 & 56 & T1-2NO & Peritumoral & SulphColl & 15 & NA & Dynamic & Probe & $\begin{array}{c}\text { Tumorectomy }^{* *}+ \\
\text { SLNB +ND }\end{array}$ & 2 & $\begin{array}{l}\mathrm{HE} ; \\
\text { SSS; } \\
\text { INMH }\end{array}$ & 952 & 95.2 \\
\hline $\begin{array}{l}\text { Broglie et } \\
\text { al. }{ }^{[24} 2013\end{array}$ & 111 & 61 & T1-2NO & NA & NA & NA & NA & $\begin{array}{c}\text { Dynamic; } \\
\text { s t a t i c } \\
\text { SPECT-CT }\end{array}$ & Probe & $\begin{array}{l}\text { Tumorectomy* + } \\
\text { SLNB + ND if SN+ }\end{array}$ & NA & NA & 93 & 95 \\
\hline $\begin{array}{l}\text { Chone et } \\
\text { al: }{ }^{[2]} 2013\end{array}$ & 46 & 55 & T1-2NO & Peritumoral & SulphColl & 12 & $\begin{array}{c}0.5 \mathrm{~mL} / \\
\text { day }\end{array}$ & Static & Probe & $\begin{array}{c}\text { Tumorectomy }^{*}+ \\
\text { SLNB + ND }\end{array}$ & $>1$ & $\begin{array}{c}\mathrm{HE} ; \\
\text { SSS; } \\
\text { INMHCTK }\end{array}$ & 92 & 98 \\
\hline $\begin{array}{l}\text { Broglie and } \\
\text { Stoeckli[ } \\
2011\end{array}$ & 79 & 60 & T1-2N0 & Peritumoral & NA & NA & NA & $\begin{array}{l}\text { Dynamic; } \\
\text { s t a t i c } \\
\text { SPECT-CT }\end{array}$ & Probe & $\begin{array}{l}\text { Tumorectomy }{ }^{*}+ \\
\text { SLNB + ND if SN+ }\end{array}$ & NA & NA & 88 & 94 \\
\hline $\begin{array}{l}\text { Ross et } \\
\text { al. }{ }^{[29]} 2002\end{array}$ & 48 & 59 & TX-NO & Peritumoral & Nanocoll & 37 & NA & $\begin{array}{l}\text { Dynamic; } \\
\text { static }\end{array}$ & $\begin{array}{c}\text { Probe; } \\
\text { BLUEDYE }\end{array}$ & $\begin{array}{l}\text { Tumorectomy* + } \\
\text { SLNB + ND if SN+ }\end{array}$ & NA & $\begin{array}{c}\text { HE; } \\
\text { SSS; } \\
\text { INMHCTK }\end{array}$ & 94 & 96 \\
\hline $\begin{array}{l}\text { Ross et } \\
\text { al. }{ }^{[30]} 2004\end{array}$ & 125 & 58 & T1-2NO & Peritumoral & $\begin{array}{l}\text { Nanocoll; } \\
\text { SulphColl }\end{array}$ & NA & NA & Static & $\begin{array}{c}\text { Probe; } \\
\text { BLUEDYE }\end{array}$ & $\begin{array}{l}\text { Tumorectomy* + } \\
\text { SLNB + ND if SN+ }\end{array}$ & - NA & $\begin{array}{c}\text { HE; } \\
\text { SSS; } \\
\text { INMHCTK }\end{array}$ & 93 & 96 \\
\hline
\end{tabular}

Nanocoll: Tc99m-Nanocololloid; SulfColl: Tc99m-sulphure colloid; FHSPECT: free hand single photon emission computed tomography; Tumorectomy*. tumorectomy prior to SLNB; Tumorectomy**: tumorectomy after SLNB; Tumorectomy§: sometimes prior to SLNB and sometimes after SLNB; HE: hematoxylin and eosin staining; SSS: serial step sectioning; INMH CTK: anti-cytokeratin immunohistochemistry; NA: not available; SLNB: sentinel lymphatic node biopsy; ND: neck dissection; SN: sentinel node; SS: sensitivity; SPECT-CT: single photon emission computed tomography-computed tomography; NPV: negative predictive value

Observation approach carries with it the risk that many patients with microscopic metastasis will be unsalvageable by the time their recurrence is detected. Hence, ND is commonly favored because of a lowered risk of uncontrolled disease. However, elective treatment in all comers has the disadvantage of unnecessary neck dissection in the majority of patients who are without microscopic cervical metastasis. ${ }^{[12]}$

With the developments of imaging tomographic techniques like single photon CT (SPECT) and hybrid techniques combining SPECT with CT (SPECT-CT) the identification of sentinel nodes has improved compared to conventional scintigraphy. ${ }^{[13]}$
In clinical trials on OSCC performed both in Europe and North America, SLNB has been shown to have predictably high accuracy in identifying occult metastasis. SN identification rates, as well as accuracy of staging of lymphatic spread, are comparable with those reported in melanoma and breast cancer, where this procedure is used routinely in patient care. ${ }^{[14-16]}$

The purpose of this study was to conduct a systematic review of the published literature to assess the state of the art of this procedure focused on the role of the SNB in the OSCC. We have evaluated the advantages of SNB compared to ND and its limitations, testing different solutions and innovations that could implement the conventional 
Table 2: Values of survival in terms of DFS, OS and DSS respect to the different histopathological findings in the articles cited

\begin{tabular}{lcccc}
\hline Stuides & Histological findings & DFS & OS & DSS \\
\hline Broglie et al. ${ }^{[2]]}$ & Total & 85 & 80 & 87 \\
2013 & Negative SLNB & 96 & 88 & 96 \\
& Positive SLNB & 73 & 74 & 77 \\
& ITC & 80 & 80 & 80 \\
& Micrometastases & 69 & 75 & 75 \\
Broglie and & Macrometastases & 62 & 62 & 73 \\
Stoeckli[ $^{[2]} 2011$ & Total & 89 & 88 & 91 \\
& Negative SLNB & 98 & 98 & 95 \\
& Positive SLNB & 73 & 71 & 76 \\
& ITC & 75 & 89 & 75 \\
& Micrometastases & 71 & 71 & 66 \\
& Macrometastases & 67 & 67 & 65 \\
\hline
\end{tabular}

SLNB: sentinel lymphatic node biopsy; ITC: isolated tumoral cells; DFS: disease free survival; OS: overall survival; DSS: disease specific survival

procedure in the best way.

\section{METHODS}

We searched the medical literature analysis and retrieval system online (MEDLINE), databases via OVID and Saludteca (Virtual Library of Extremadura Public Health System) for relevant studies published in English from January 2011 to January 2016, limited to human subjects. The combination of search terms used was the following: (1) sentinel node; (2) oral; and (3) squamous cell cancer. The abstracts were reviewed one by one and applying the inclusion criteria. The inclusion criteria were the following: (1) original studies; (2) prospective studies; (3) studies evaluating the role SLNB in OSCC in N0 patients; and (4) at least 30 subjects included in the study. Meta-analysis and review articles were collected in order to establish the introduction and support the data in the discussion of the article. The references of these latter works were examined and all interesting articles were included for the elaboration of this review.

\section{Data extraction}

For each study, we extracted data on the author's name, year, type of study, characteristics of patients, staging of the tumour, type of radiotracer, amount of activity and volume injected per dose of radiotracer, type of images acquired, method of analysis of images, types of radioguided surgery equipment employed, surgical technique employed, histological techniques for evaluating the SN, sensitivity (SS), negative predictive value (NPV), patients survival in terms of disease-free survival (DFS), overall survival (OS) and disease-specific survival (DSS).

All parameters involved in the SNB technique were examined in the articles; they were analyzed in order to determine which one would be the most reasonable and useful to establish the state of the art of the procedure.

\section{RESULTS}

The literature search yielded a total of 219 potential articles [Figure 1]. When we established the second limits (English articles, of the last 5 years and only human studies) we excluded 150 articles. After screening the titles and abstracts of the remaining 69 articles, applying the third selection (prospective studies, TxN0, 30 patients at least) we selected 12 articles. $^{[12,16-26]}$ Together with two additional prospective $\operatorname{articles}^{[27,28]}$ identified from reviews and references, a total of 14 articles were included in this systematic review. Table 1 summarizes all the studies included providing the details of the individual studies (full database available from author). Table 1 summarizes the pooled sensitivity and negative predictive values of the SNB. Six out of fifteen of these articles also include survival data [Table 2] in terms of OS, DFS and DSS. All articles studied OSCC T1-2N0 except two that included any $\mathrm{T}$ and $\mathrm{N} 0$.

Regarding the radio-isotopic technique employed, 7 authors used colloid sulfur radiolabeled with Technetium99m (Tc99m-colloidsulfur) and other 5 nanocolloid radiolabeled with Tecnetium99m (Tc99m-nanocolloid). One of this latter combined with immunoglobulins. In the two remaining studies these data were not available. All authors employed peritumoral injection. The activity injected was detailed in 12 articles and ranged between 10-80 MBq each dose (mean $\pm 20 \mathrm{MBq})$. In 9 studies the dose ranged between 10 and $20 \mathrm{MBq}$. The volume of tracer injected per dose was only described in 6 articles and ranged between 0.05 and $0.5 \mathrm{~mL}$ (mean $\pm 0.23 \mathrm{~mL}$ ).

The imaging technique employed was detailed in 13 studies, performing dynamic images after tracer administration and static planar conventional images at $2 \mathrm{~h}$ in 6 cases. Three authors only performed static planar conventional images $2 \mathrm{~h}$ after tracer administration. One work included dynamic, static and SPECT images. Three studies carried out dynamic, static and hybrid SPECT-CT images. In 4 works blue dye was injected in the surgical room for improving the identification of the sentinel node according to their color and radioactivity. ${ }^{[12,18,27,28]}$

For the intraoperative SN localization, the equipment employed was as follows: only radioguided probe in 8 cases, radioguided probe and blue dye colorant in 3 cases, combined radioguided probe and portable gamma-camera in 1 case and 1 work employed a novel detection system with intrasurgical free-hand SPECT (SurgicEye $\left.{ }^{\odot}\right){ }^{[20]}$

Regard the surgical technique employed, in eleven works a tumorectomy was first performed and immediately a SNB. If the result of SNB showed any lymphatic node affected, a ND was carried out in 9 studies. In the remaining 5 studies, tumorectomy, SNB and ND was performed in all patients.

The number of biopsied nodes was detailed in 9 works, with a mean of 3 nodes per patient. The nodes was studied in 10 studies by mean of histological techniques that include hematoxylin-eosin (HE) staining, step serial section (SSS) and immunohistochemistry $(\mathrm{IHC})$ analysis for cytokeratin $\mathrm{AE} 1 / \mathrm{AE} 3$, in order to confirm the absence of metastatic lymph nodal disease. In 1 article only HE and IHC techniques were employed. ${ }^{[12]}$ In three works, these data were not available.

SS values ranged in all studies between $80 \%$ and $100 \%$ (mean 
$\pm 94.2 \%$ ). NPV were available in 13 studies reaching values between $88 \%$ and $100 \%$ (mean $\pm 94.4 \%$ ).

In only 5 works, the survival data were displayed in terms of DFS, OS and DSS regard the SLNB results. These 5 works showed the data detailing the positivity or negativity of the nodes biopsied. In only 2 studies the terms of survival were also displayed depending of the type of node invasion, isolated tumoral cells (ITC), micrometastases or macrometastases. ${ }^{[24,26]}$ All type of node invasion showed significant differences in terms of DFS, OS and DSS respect to the absence of node invasion. The two works were published by Broglie et al ${ }^{[24,26]}$ in 2011 and 2013 obtaining very similar values for DFS for the pathological results of SNB negative, ITC, micrometastases and macrometastases. Those results were: $96 \%$ and $98 \%, 80 \%$ and $75 \%, 69 \%$ and $71 \%$, $62 \%$ and $67 \%$, respectively. The values obtained for OS for the same pathological results were: $88 \%$ and $98 \%, 80 \%$ and $89 \%, 75 \%$ and $71 \%, 62 \%$ and $67 \%$, respectively. Finally, the values obtained for DSS for those pathological results were: $96 \%$ and $95 \%, 80 \%$ and $75 \%, 75 \%$ and $66 \%, 73 \%$ and $65 \%$, respectively [Table 2].

\section{DISCUSSION}

SNB is a well contrasted technique for the regional evaluation of tumor staging in breast cancer and melanoma included in international guidelines of management of these tumors. ${ }^{[10,11]}$ However, in OSCC it still remains with an investigational role. This procedure is very complicated in head and neck tumors because of the great wealth of lymphatic vessels and a great variability of regional lymphatic migration. We selected articles published in the last 5 years, as accumulated experience has induced some evolution in radioisotope procedures, imaging techniques and radio-surgery procedures. We included 2 interesting prospective papers published in 2002 and 2004 because they reach every required criteria, with high number of patients and included detailed data of survival respect to the histological findings of IHC. ${ }^{[27,28]}$

We selected only prospective studies because they imply an approach and prior review of the different techniques used. In OSCC, the first studies have only been published since 1999, 7 years after the technique gained acceptance in breast and melanoma. This, combined with the reduced incidence of oral cancers compared to melanoma and breast cancer, necessarily results in a low number of studies with more than 30 patients, but it is similar to some meta-analysis reviewed. ${ }^{[29]}$

\section{Radiotracer}

Seven studies employed Tc99m-nanocolloid as radiotracer and 6 used Tc99m-sulphur colloid [Table 1]. Values of SS and NPV ranged between $88-100 \%$ and $86-100 \%$ with Tc99mnanocolloid, and between $80-95 \%$ and $93-98 \%$ with sulphur colloid. The number of studies is very low but there were no significant differences.

Several 99mTc-based agents have been used for radioguided SNB. The ideal radiotracer should show rapid transit to SNs with prolonged retention in the nodes. In general, the drainage, distribution, and clearance of radioactive colloids by the lymphatic system may vary and are dependent on the size of the particles. Small particles are drained and cleared first; large particles are drained and cleared last and may be retained longer at the injection site. There is worldwide variation in radiopharmaceuticals used for lymphoscintigraphy. Tc-99m sulphur colloid is employed in the USA, with an average size ranging from $305 \mathrm{~nm}$ to 340 $\mathrm{nm}$ and Tc-99m-nanocolloid are used in Europe with size ranging from $5 \mathrm{~nm}$ to $100 \mathrm{~nm} .^{[30]}$ Studies have shown that the success rate of identification of SNs is not significantly affected by the particle size of the radiotracer. ${ }^{[31-34]}$ Thus, the selection of radiotracer is based more on local availability than on differences in sentinel lymph node (SLN) detection.

Recent developments in new tracers are coming, like the use of indocyanine green-Tc99m-nanocolloid, a hybrid tracer that is both radioactive and fluorescent. The addition of fluorescence imaging was shown to be of particular value when SNs were located in close proximity to the primary tumour. ${ }^{[3]}$

Tilmanocept ${ }^{\odot}$, is another novel receptor-targeted radiopharmaceutical, Tc99m-labeled non-particulate radiotracer with high affinity for the macrophages and dendritic cells, within the sentinel lymph node. Studies have been promising, with suggestions that tilmanocept may have improved clearance from the site of the primary tumor and enhanced retention within the sentinel node when compared to sulfur colloid. ${ }^{[36]}$

Based upon the experience accumulated in SNLB in other tumors, consensus on the activity to be administered in a SNB procedure has not been reached. The investigated and suggested activities vary considerably. Activities as low as $3.7 \mathrm{MBq}(0.1 \mathrm{mCi})^{[37]}$ and as high as $370 \mathrm{MBq}(10 \mathrm{mCi})^{[36]}$ have been used. In our review, the doses ranged between 10 and $80 \mathrm{MBq}$, the adequate dose if the tracer administration is performed the day before surgery, especially if we are going to acquire SPECT-CT images that require greater tracer activity. These doses do not imply a significant radiation dose to the workers in the operation room. Note that between administration of the radiotracer and surgery usually pass at least $24 \mathrm{~h}$. It means that an administered dose will become to $1 / 16$ of the injected at the operation time, so that no specific radioprotection precautions are required.

\section{Radiotracer administration}

Respect to the volume of radiotracer injected, Chone et al. ${ }^{[25]}$ employed the largest volume per dose $(0.5 \mathrm{~mL})$ in an attempt to completely surround the tumor in its deep and lateral aspects at a sub-mucous level of normal mucous membrane that surrounds the tumor in a volume of approximately 1-2 mL. However, we did not find any significant difference in terms of SS or NPV. In breast cancer with peritumoral injections, larger volumes per dose (i.e. 0.5-1.0 mL) are preferred for the same reason. ${ }^{[33]}$ Perhaps the best option would be to try the peritumoral region completely surrounded by the radiotracer to avoid false negative results.

\section{SN preoperative localization}

The most common method to preoperatively localize $\mathrm{SN}$ included injecting a radioactive sentinel node tracer 
followed by lymphoscintigraphy, without the use of blue dye. Its use may also facilitate SLN detection during surgery but there were no significant differences in terms of SS or NPV. It highlights the fact that the lowest value of SS was obtained in a job that used blue dye. ${ }^{[18]}$

False-negatives can occur through multiple mechanisms, including incomplete or inadequate peritumoral injection, obscuring of the SN by shine-through of the radioactive signal at the primary tumor site, and lymphatic obstruction secondary to tumor-obstructed nodes resulting in redirection of lymphatic flow. ${ }^{[14]}$

Nine authors employed dynamic images in a trend to identify the lymphatic migration to the sentinel nodes. To date; the predominant clinical experience with SNB has been with oral cavity tumors. There is still some debate in the literature regarding the accuracy of SNB for floor of mouth tumors compared to other oral locations. ${ }^{[38-40]}$ The argument by those who report a lower sensitivity and negative predictive value for floor of mouth tumors compared to other locations is that tumors in the floor of mouth lie in very close proximity to level I nodes leading to difficulty in identifying and harvesting SLNs. ${ }^{[14,40]}$ Antonio et al. ${ }^{[2]}$ state that the minimum treatment of the neck is probably dissection of the levels between the primary tumour and the level containing the $\mathrm{SN}(\mathrm{s})$.

This problem can be solved by means of tomographic imaging techniques that can separate tracer uptake of adjacent organs, especially the hybrid techniques such as SPECT-CT that by their much greater anatomical resolution and image quality are much more appropriate. It is noteworthy that only three authors use these techniques to help more accurately identifying lymph node stations in various forms, as well as its relations with adjacent structures. $^{[13]}$

\section{Intraoperative procedure}

In the surgical room, radioguided surgical probe was employed in 11 articles; one of them with a portable intraoperative gamma-camera added. ${ }^{[16]}$ When we use exclusively a probe it is recommended to previously identify the $\mathrm{SN}$ and its anatomical location based upon the images examination and labeling marks on the skin of the patient. For this, a close collaboration between the physicians of nuclear medicine and surgeons is recommended. In order to avoid or minimize the shine-through effect, the surgeon must perform a lumpectomy before the SNB. After lumpectomy, additional images can be acquired with portable gammacamera and identify the $\mathrm{SN}$ of the regions close to the tumor that could be missed in the initial images.

Bluemel et al ${ }^{[20]}$ used a new detection system based on a freehand SPECT performed in the operating room before surgery and even intraoperatively after lumpectomy in a short period of time (less than $2 \mathrm{~min}$ ) that eliminated the peritumoral tracer activity and improved the location of those lymphatic echelons close to the tumor and eliminating the shine-through effect.
There was no agreement in which would be the adequate number of SN biopsied. This fact remains controversial in OSCC because of the possibility of great number of SN, variability of different lymphatic echelons, frequent contralateral migration, etc. Perhaps it would be wise to excise at least, all hot cervical nodes found in the images.

\section{Histological techniques}

Histological techniques employed are a crucial point in the SNB process. All items with available data, except one, employed HE, SSS and IHC analysis for citokeratin. All remarked the importance of the three techniques for reaching the highest accuracy. On the other hand, one of the biggest potential downsides to a strategy of SNB as compared with upfront elective ND is the need to return to the operating room on a separate occasion for a completion ND for a positive SLNB. Although immediate intraoperative frozen section can identify a significant proportion of patients with a positive SNB, there remains a subset of patients whose occult disease will only become apparent with SSS and IHC analysis. ${ }^{[25]}$ The increased morbidity, cost and delay in healing that comes from a second procedure are viewed by many as an obstacle to the implementation of SNB. Some authors attempted to develop a more efficient method for the intraoperative genetic detection of lymph node metastasis in head and neck aquamous cell carcinoma using the one-step nucleic acid amplification (OSNA) method of cytokeratin-19. ${ }^{[41]}$

\section{Perspectives}

The data founded showed that any type of neoplastic spread to the SN imply significant differences in terms of survival [Table 2]. The presence of micrometastases and macrometastases must be followed by ND in order to control the disease. This probably means that more survival specific studies are necessary to clarify the role of ITC in SN. According to the guidelines in early breast cancer, complete axillary lymph node dissection is recommended if SNB is positive except for ITCs. ${ }^{[42]}$ However, the reviewed studies suggested that the presence of even small tumor-cell deposits in lymph nodes reflects the potential of the primary tumor to metastasize and, for the time being, completion elective neck dissection should be performed irrespectively of the size of metastases. ${ }^{[24,26]}$

Based upon this review, we can resume the protocol of SNB as follows: (1) close collaboration between the departments of maxillofacial surgery, oncology, radiology and nuclear medicine is recommended; (2) the selection of radiotracer is based more on local availability than on differences in SLN detection. In our mean, Tc99m-nanocolloid should be employed. In the future, attention must be focused on new tracers; (3) activity dose per injection will range between 37-74 MBq if surgery is performed the day after the tracer administration; (4) peritumoral injection will be performed trying to surround the lesion as much as possible to avoid false negative results; (5) the volume per dose recommended will reach $0.5 \mathrm{~mL}$ in a trend to completely surround the tumor in a total volume of $1-2 \mathrm{~mL}$; (6) imaging techniques should include tomographic studies, especially hybrid SPECT- 
CT techniques, if available, in a trend to avoid shine-through effect and identify SN in lymphatic echelons close to the tracer injection. Free-hand intraoperative SPECT technique will be an interesting choice in the future; (7) tumorectomy will be performed previous to SNB to avoid shine-through effect helping to identify SN in lymphatic spaces I and II; (8) $\mathrm{SN}$ will be studied with histological exhaustive techniques including $\mathrm{HE}$, SSS and IHC to reach the highest accuracy to identify occult disease. In the future, OSNA techniques could be developed but more studies are necessary to evaluate these; and (9) if SN shows a positive result a ND will be mandatory. There are only doubts about the role of ITCs in SN, but the current data suggest that any neoplastic presence in $\mathrm{SN}$ recommend a ND.

In conclusion, SNB is a well-known powerful tool in the management of some tumors like breast cancer and melanoma. In early-stage oral cavity cancer, SNB is gaining acceptance worldwide as an effective alternative to elective neck dissection for staging the NO neck. Nowadays, despite anatomical and functional differences of this region, the available evidence suggests that SNB accurately stages the neck with a reasonable false-negative rate.

False-negatives can occur through multiple mechanisms, including incomplete or inadequate peritumoral injection, obscuring of the $\mathrm{SN}$ by shine-through of the radioactive signal at the primary tumor site, and lymphatic obstruction secondary to tumor-obstructed nodes resulting in redirection of lymphatic flow. The use of adequate radiotracer and proper injection as well as the optimal employment of imaging procedures and surgical techniques can help solving this limitation.

Given the increased risk of morbidity with selective neck dissection or radiation therapy, and the decreased survival with watchful waiting, the SNB may provide a reasonable alternative when done by an experienced multidisciplinary group of surgeons, radiologists, oncologists and nuclear medicine physicians.

Recent advances are focused on the development of novel radiotracers imaging techniques and molecular assays, to improve the intraoperative identification of SN. They may help to overcome some of the obstacles to widespread implementation of SNB for OSCC NO.

\section{Financial support and sponsorship}

Nil.

\section{Conflicts of interest}

There are no conflicts of interest.

\section{REFERENCES}

I. Thompson CF, St John MA, Lawson G, Grogan T, Elashoff D, Mendelsohn $\mathrm{AH}$. Diagnostic value of sentinel lymph node biopsy in head and neck cancer: a meta-analysis. Eur Arch Otorhinolaryngol 201 3;270:21 I 5-22.

2. Antonio JK, Santini S, Politi D, Sulfaro S, Spaziante R, Alberti A, Pin M, Barzan L. Sentinel lymph node biopsy in squamous cell carcinoma of the head and neck: 10 years of experience. Acta Otorhinolaryngol Ital 2012;32:18-25.
3. Ferris RL, Xi L, Seethala RR, Chan J, Desai S, Hoch B, Gooding W, Godfrey TE. Intraoperative qRT-PCR for detection of lymph node metastasis in head and neck cancer. Clin Cancer Res 201 I; 17:1858-66.

4. Shoaib T, Soutar DS, MacDonald DG, Camilleri IG, Dunaway DJ, Gray HW, McCurrach GM, Bessent RG,MacLeod TI, Robertson AG. The accuracy of head and neck carcinoma sentinel lymph node biopsy in the clinically NO neck. Cancer 200I;91:2077-83.

5. Kligerman J, Lima RA, Soares JR, Prado L, Dias FL, Freitas EQ, Olivatto LO Supraomohyoid neck dissection in the treatment of TI/T2 squamous cell carcinoma of oral cavity. Am J Surg 1994; I68:39|-4.

6. McGuirt WF Jr, Johnson JT, Myers EN, Rothfield R, Wagner R. Floor of mouth carcinoma. The management of the clinically negative neck. Arch Otolaryngol Head Neck Surg 1995; 121:278-82

7. Taylor RJ, Wahl RL, Sharma PK, Bradford CR, Terrell JE, Teknos TN, Heard EM, Wolf GT, Chepeha DB. Sentinel node localization in oral cavity and oropharynx squamous cell cancer. Arch Otolaryngol Head Neck Surg 200I;I27:970-4.

8. Pillsbury HC, Clark M.A rationale for therapy of the N0 neck. Laryngoscope 1997;107:1294-3|5.

9. Murer K, Huber GF, Haile SR, Stoeckli SJ. Comparison of morbidity between sentinel node biopsy and elective neck dissection for treatment of the $\mathrm{n} 0$ neck in patients with oral squamous cell carcinoma. Head Neck 2011;33:1260-4.

10. Buscombe J, Paganelli G, Burak ZE, Waddington W, Maublant J, Prats E, Palmedo H, Schillaci O, Maffioli L, Lassmann M, Chiesa C, Bombardieri E, Chiti A; European Association of Nuclear Medicine Oncology Committee and Dosimetry Committee. Sentinel node in breast cancer procedural guidelines. Eur J Nucl Med Mol Imaging 2007;34:2154-9.

II. Bluemel C, Herrmann K, Giammarile F, Nieweg OE, Dubreuil J, Testori A, Audisio RA, Zoras O,Lassmann M, Chakera AH, Uren R, Chondrogiannis S, Colletti PM, Rubello D. EANM practice guidelines for lymphoscintigraphy and sentinel lymph node biopsy in melanoma. Eur J Nucl Med Mol Imaging 20I5;42:1750-66.

12. Samant S. Sentinel node biopsy as an alternative to elective neck dissection for staging of early oral carcinoma. Head Neck 2014;36:24I-6.

13. Serrano-Vicente J, Rayo-Madrid JI, Domínguez-Grande ML, Infante-Torre JR, García-Bernardo L, Moreno-Caballero M, Medina-Romero F, DuránBarquero C. Role of SPECT-CT in breast cancer sentinel node biopsy when internal mammary chain drainage is observed. Clin Transl Oncol 2016;18:4|8-25

14. Civantos FJ, Zitsch RP, Schuller DE, Agrawal A, Smith RB, Nason R, Petruzelli G, Gourin CG, Wong RJ, Ferris RL, El Naggar A, Ridge JA, Paniello RC, Owzar K, McCall L, Chepeha DB, Yarbrough WG, Myers JN. Sentine lymph node biopsy accurately stages the regional lymph nodes for TI-T2 oral squamous cell carcinomas: results of a prospective multi-institutional trial. J Clin Oncol 2010;28:1395-400.

15. Govers TM, Hannink G, Merkx MA, Takes RP, Rovers MM. Sentinel node biopsy for squamous cell carcinoma of the oral cavity and oropharynx: a diagnostic meta-analysis. Oral Oncol 2013;49:726-32.

16. Salazar-Fernandez Cl, Gallana-Alvarez S, Pereira S, Cambill T, InfanteCossio P, Herce-Lopez J. Sentinel lymph node biopsy in oral and oropharyngeal squamous cell carcinoma: statistical validation and impact of micrometastasis involvement on the neck dissection decision. J Oral Maxillofac Surg 2015;73:1403-9.

17. Farmer RW, McCall L, Civantos FJ, Myers JN, Yarbrough WG, Murphy B, O'Leary M, Zitsch R, Siegel BA. Lymphatic drainage patterns in oral squamous cell carcinoma: findings of the ACOSOG Z0360 (Alliance) study. Otolaryngol Head Neck Surg 20 I5; I 52:673-7.

18. Flach GB, Bloemena E, Klop WM, van Es RJ, Schepman KP, Hoekstra OS, Castelijns JA, Leemans CR, de Bree R. Sentinel lymph node biopsy in clinically NO TI-T2 staged oral cancer: the Dutch multicenter trial. Oral Oncol 20I4;50:1020-4.

19. Hernando J, Villarreal P, Alvarez-Marcos F, Gallego L, García-Consuegra L, Junquera L. Comparison of related complications: sentinel node biopsy versus elective neck dissection. Int J Oral Maxillofac Surg 20 I4;43: I 307-I 2.

20. Bluemel C, Herrmann K, Kübler A, Buck AK, Geissinger E, Wild V, Hartmann S, Lapa C, Linz C, Müller-Richter U. Intraoperative 3-D imaging improves sentinel lymph node biopsy in oral cancer. Eur J Nucl Med Mol Imaging 20| 4;41:2257-64.

21. Alvarez J, Bidaguren A, McGurk M, Diaz-Basterra G, Brunsó J,Andikoetxea B, Martín JC, Barbier L, Arteagoitia I, Santamaría JA. Sentinel node biopsy in relation to survival in floor of the mouth carcinoma. Int J Oral Maxillofac Surg $2014 ; 43: 269-73$.

22. Bell RB, Markiewicz MR, Dierks EJ, Gregoire CE, Rader A. Thin serial step sectioning of sentinel lymph node biopsy specimen may not be necessary to accurately stage the neck in oral squamous cell carcinoma. J Oral 
Maxillofac Surg 2013;7I:I268-77.

23. Melkane AE, Mamelle G, Wycisk G, Temam S, Janot F, Casiraghi O, Lumbroso J. Sentinel node biopsy in early oral squamous cell carcinomas: a I0-year experience. Laryngoscope 2012 ; I22: 1782-8.

24. Broglie MA, Haerle SK, Huber GF, Haile SR, Stoeckli SJ. Occult metastases detected by sentinel node biopsy in patients with early oral and oropharyngeal squamous cell carcinomas: impact on survival. Head Neck 2013;35:660-6.

25. Chone CT, Aniteli MB, Magalhães RS, Freitas LL, Altemani A, Ramos CD, Etchebehere E, Crespo AN. Impact of immunohistochemistry in sentinel lymph node biopsy in head and neck cancer. Eur Arch Otorhinolaryngol 2013;270:3 I3-7.

26. Broglie MA, Stoeckli SJ. Relevance of sentinel node procedures in head and neck squamous cell carcinoma. Q J Nucl Med Mol Imaging 20 I I;55:509-20.

27. Ross G, Shoaib T, Soutar DS, Camilleri IG, Gray HW, Bessent RG, Robertson AG, MacDonald DG. The use of sentinel node biopsy to upstage the clinically NO neck in head and neck cancer. Arch Otolaryngol Head Neck Surg 2002; 128: 1287-91.

28. Ross GL, Soutar DS, Gordon MacDonald D, Shoaib T, Camilleri I, Roberton AG, Sorensen JA, Thomsen J, Grupe P,Alvarez J, Barbier L, Santamaria J, Poli T, Massarelli O, Sesenna E, Kovács AF, Grünwald F, Barzan L, Sulfaro S, Alberti F. Sentinel node biopsy in head and neck cancer: preliminary results of a multicenter trial. Ann Surg Oncol 2004; I I:690-6.

29. Paleri V, Rees G, Arullendran P, Shoaib T, Krishman S. Sentinel node biopsy in squamous cell cancer of the oral cavity and oral pharynx: a diagnostic meta-analysis. Head Neck 2005;27:739-47.

30. Wilhelm AJ, Mijnhout GS, Franssen EJ. Radiopharmaceuticals in sentinel lymph-node detection-an overview. Eur J Nucl Med 1999;26:S36-42.

31. Mariani G, Moresco I,Viale G,Villa G, Bagnasco M, Canavese G, Buscombe J, Strauss HW, Paganelli G. Radioguided sentinel lymph node biopsy in breast cancer surgery.J Nucl Med 200 I;42:I I 98-2I5.

32. Clarke D, Khoni NL, Mansel RE. Sentinel node biopsy in breast cancer. ALMANAC trial. World J Surg 200I;25:819-22.

33. Bourgeois P. Scintigraphic investigations of the lymphatic system: the influence of injected volume and quantity of labeled colloidal tracer. J Nucl Med 2007;48:693-5.

34. Burak WE Jr, Agnese DM, Povoski SP.Advances in the surgical management of early stage invasive breast cancer. Curr Probl Surg 2004;41:877-936.
35. Van den Berg NS, Brouwer OR, Klop WM, Karakullukcu B, Zuur CL, Tan IB, Balm AJ, van den Brekel MW, Valdés Olmos RA, van Leeuwen FW. Concomitant radio- and fluorescence-guided sentinel lymph node biopsy in squamous cell carcinoma of the oral cavity using ICG-(99m)Tcnanocolloid. Eur J Nucl Med Mol Imaging 20I2;39: I I 28-36.

36. Sondak VK, King DW, Zager JS, Schneebaum S, Kim J, Leong SP, Faries MB, Averbook BJ, Martinez SR, Puleo CA, Messina JL, Christman L,Wallace AM. Combined analysis of phase III trials evaluating [99mTc]tilmanocept and vital blue dye for identification of sentinel lymph nodes in clinically nodenegative cutaneous melanoma. Ann Surg Oncol 20I 3;20:680-8.

37. McCarter MD, Yeung H, Yeh S, Fey J, Borgen PI, Cody HS 3rd. Localization of the sentinel node in breast cancer: identical results with same-day and day-before isotope injection. Ann Surg Oncol 200I;8:682-6.

38. Tomifuji M, Shiotani A, Fujii $H$, Araki K, Saito K, Inagaki K, Mukai M, Kitagawa Y, Ogawa K. Sentinel node concept in clinically n0 laryngeal and hypopharyngeal cancer. Ann Surg Oncol 2008;15:2568-75.

39. Jeong HS, Baek CH, Son YI, Cho DY, Chung MK, Min JY, Ko YH, Kim BT. Sentinel lymph node radiolocalization with $99 \mathrm{mTc}$ filtered tin colloid in clinically node-negative squamous cell carcinomas of the oral cavity. J Korean Med Sci 2006;21:865-70.

40. Mozzillo N, Chiesa F, Caracò C, Botti G, Lastoria S, Longo F, lonna F. Therapeutic implications of sentinel lymph node biopsy in the staging of oral cancer. Ann Surg Oncol 2004; I I:S263-6.

4I. Goda H, Nakashiro K, Oka R, Tanaka H, Wakisaka H, Hato N, Hyodo M, Hamakawa $\mathrm{H}$. One-step nucleic acid amplification for detecting lymph node metastasis of head and neck squamous cell carcinoma. Oral Oncol 20I2;48:958-63.

42. Carlson RW, Allred DC, Anderson BO, Burstein HJ, Carter WB, Edge SB, Erban JK, Farrar WB, Goldstein LJ, Gradishar WJ, Hayes DF, Hudis CA, Jahanzeb M, Kiel K, Ljung BM, Marcom PK, Mayer IA, McCormick B, Nabell LM, Pierce LJ, Reed EC, Smith ML, Somlo G, Theriault RL, Topham NS, Ward JH, Winer EP, Wolff AC; NCCN Breast Cancer Clinical Practice Guidelines Panel. Breast cancer. Clinical practice guidelines in oncology. J Natl Compr Canc Netw 2009;7:122-92. 